\title{
Low Grade Penile Intraepithelial Neoplasia
}

National Cancer Institute

\section{Source}

National Cancer Institute. Low Grade Penile Intraepithelial Neoplasia. NCI Thesaurus.

Code C7666.

Penile intraepithelial neoplasia characterized by the proliferation of transformed basaloid cells that occupy the lower one third of the epithelial thickness. 